\title{
TECHNIQUES OF MEASUREMENT OF IMPACT RESPONSE OF THE THORAX IN BIOMECHANICAL EXPERIMENTS- PART I: INSTRUMENTATION
}

\author{
by G.S. Nusholtz
}

\section{METHODOLOGY}

Blunt non-penetrating thoracic impacts to human surrogates have been studied at the University of Michigan Transportation Research Institute (UMTRI) for several years. ${ }^{1.2}$ These experiments are re-creations of impact environments which might have occurred as a result of a sports accident, an industrial/military accident, or an automotive crash. Most of the experimental work has utilized the repressurized human cadaver as the impact-test subject, although infrequent comparative analyses have utilized animals. The test subject is surgically instrumented prior to testing with mounting platforms for the accelerometers, pressure transducers, or other recording devices. Later, a detailed autopsy or necropsy is performed to record the damages resulting from the impact testing.

The testing equipment usually includes: (1) an impact device to deliver a calibrated amount of energy to the thorax, (2) a timing-control unit to synchronize the electronic equipment associated with a $10.100 \mathrm{~ms}$ impact time frame, (3) a high-speed X-ray cineradiograph or cameras and lights to photographically record gross motion of the test sub. ject, (4) electromechanical accelerometers, pressure transducers, strain gages, and associated amplifiers used to measure the kinematic response (output) for a given impact condition, (5) test-

G.S. Nusholtz is Assistant Research Scientist, Transportation Research Institute, The Univer. sity of Michigan, Ann Arbor, MI.

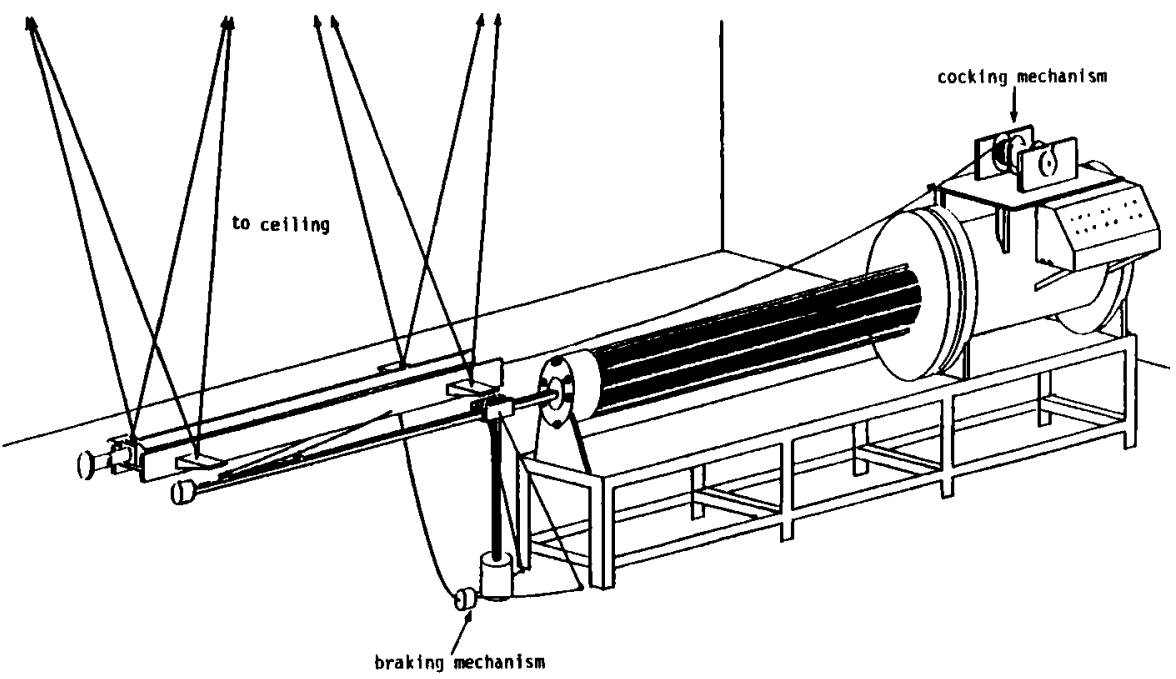

Fig. 1-Pneumatic ballistic impact device

subject repressurization equipment, and (6) FM data tape recorders to obtain electromechanical transducer time histories. Supporting systems are sometimes required to pre-position the test subject in a precise postural configuration prior to impact.

Pneumatic Impacting Device-The UMTRI pneumatic ballistic impact device (Fig. 1) consists of an air reservoir, a ground and honed cylinder, and a carefully fitted piston mechanically coupled to a ballistic pendulum. Compressed air from the building's air compression sys. tem is introduced into the reservoir. The driver piston is secured at the reservoir end of the cylinder by an electronically controlled locking mechanism. When the air reservoir is pres. surized and the locking mechanism released, the driver piston is propelled by the compressed air through the cylinder accelerating the ballistic pendulum. The impactor surface is a $10 . \mathrm{cm}$ rigid-metal plate padded with $2.5 \mathrm{~cm}$ Ensolite. The impactor-force transducer assembly consists of a Kistler piezoelectric load washer with a Kistler piezoelectric accelerometer mounted internally for inertial compensation.

To document the kinematic response of the subjects, arrays of accelerometer's were affixed to the thorax of each subject. The thorax was instrumented with 18 accelerometers; triaxial acceler. ometer clusters were rigidly attached to the right and left fourth ribs, upper sternum, and $\mathrm{T} 1$ and $\mathrm{T} 12$ thoracic vertebrae. Single accelerometers were affixed to the right and left eighth ribs and lower sternum. Surgical instrumentation involved rigidly affixing accelerometer mounting seat forms to the skeletal thorax. 


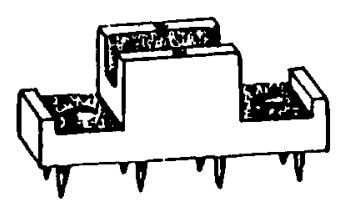

UNIAX MOUNTING PLATFORM

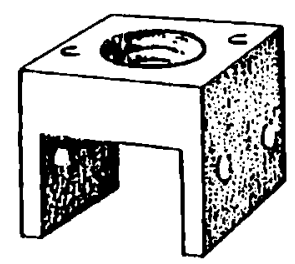

SPINAL TRIAX MOUNTING PLATFORM

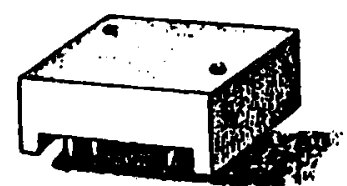

TRIAX MOUNTING PLATFORM

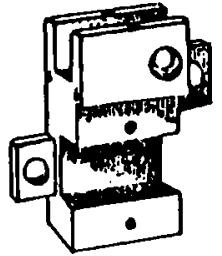

TRIAX MOUNT

\section{STMNES}

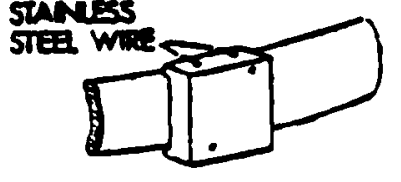

TRLAX RoB MOUNTIG PLATFORM

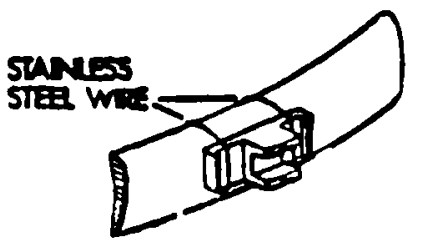

UNAX Ri. MOUNTING PLATFORM

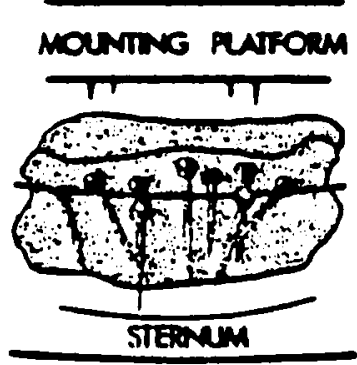

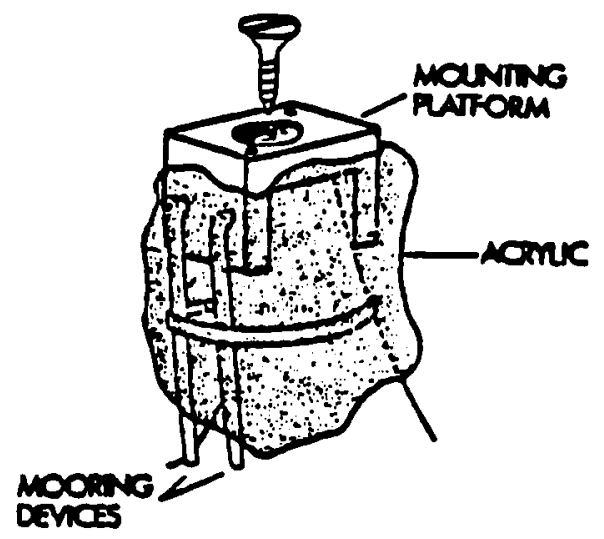

SOAEMATK PEPPESENTATON OF SPINAL MOUNTING PLATFORM
Sternum-Incisions were made at the attachment points on the sternum for the mounts. Small braided nails were tapped into the sternum, encased in acrylic, and the accelerometer mounting platform was embedded into the acrylic (Figs. 2, 3).

Ribs-Incisions were made over the fourth and eighth ribs on each side, so that the flat part of the exposed rib was normal to the lateral (anatomical) direction. To ensure rigidity, the mounts were fitted with pins and tied with wire to the flat surface of each exposed rib (Figs. 2, 3).

Fig. 3-Location of mounting platforms

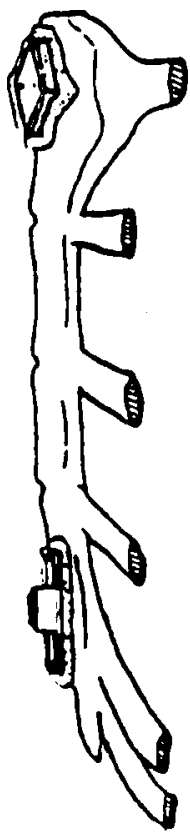


Spine-Incisions were made over the vertebrae. Lateral supports for the accelerometer mounts were anchored on the lamina bilaterally, so that they would flank the spinous process. The accelerometer mount itself was fitted over these supports and screwed directly into the spinous process. Acrylic was applied under and around the mounts to ensure rigidity (Figs. 2, 3).

Photokinemetrics-High-speed photographic coverage of the test consisted of two lateral views. A Hycam camera operating at 3000 frames per second provided a close-up view of the thorax, while a Photosonics $1 \mathrm{~B}$ camera operating at 1000 frames per second recorded an overall view of the test subject during the impact. The motion of the subject was determined from the film by following the motion of five-point phototargets on the acromion and sternum as well as "single-point" phototargets on the head and impactor piston.

Application-Analysis of the photogrammetric data and electromechanical signals provides a framework in which parameters such as forces, velocities, accelerations, and rotations can be used to describe kinematic motion and mechanisms of injury. This information then can be used for designing protective devices as well as for more advanced modelling of the observed biomechanical system. In these thoracic studies, the final goal was to understand biological material (e.g., the thorax), consisting of both hard and soft tissues, in terms of both the time and frequency domains.

\section{ACKNOWLEDGMENTS}

This work was conducted under the sponsorship of the National Highway Traffic Safety Administration, Contract Nos. DTNH22-83-C-17019 and D'TNH2283-C.07095. The author gratefully acknowledges the contributions of Robert Bennett, Richard Lehman, Valerie Karime, Bryan Suggitt, and Patricia Kaiker.
The protocol for the use of cadavers in these experiments was approved by the University of Michigan Medical Center and followed guidelines by the U.S. Public Health Service and those recommended by the National Academy of Sciences, National Research Council. Animals were handled according to the American Association for the Accreditation of Laboratory Animal Care and National Institutes of Health guidelines.

\section{REFERENCEQ}

1. Nusholtz, G., Melvin, J. and Lux, P., "The Influence of Impact Energy and Direction on Thoracic Response, 27th Stapp Car Crash Conf. Proc., 419.442 (1983).

2. Nusholtz, G., Kaiker, P., Kirsh, M. and Bosio, A., "Thoracic Response to Frontal Impact," 29th Stapp Car Crash Conf. Proc., 1-32 (1985).

Editor's Note: Part II of this article will appear in the December 1986 issue of E/T.

\section{A few words about}

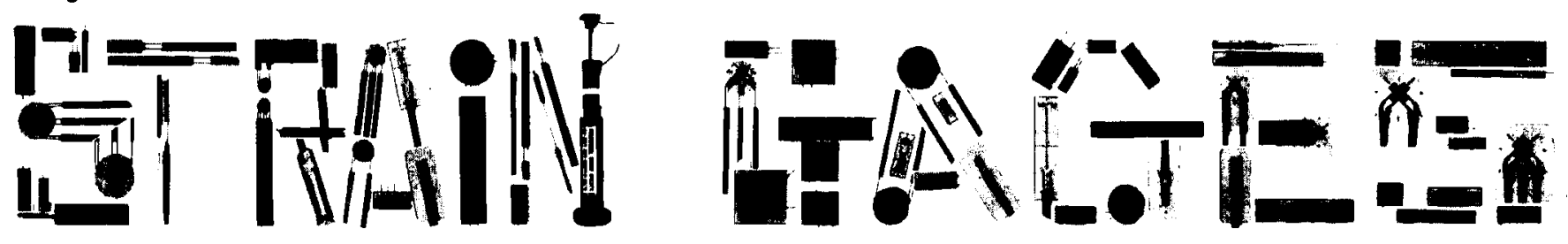

\section{from Texas Measurements, Inc. . . .}

You're already using someone's gages. There's an increasing chance they're ours, since sales have more than doubled every year since 1981. We're proud of that growth because a lot of it is from repeat customers.

We stock a wide variety of foil and wire single axis and rosette gages, plus specialty items like the concrete embedment, reuseable, and bolt gages. We have gage lengths from $1 / 128$ " to $4-3 / 4^{\prime \prime}$ for temperatures from $-300^{\circ} \mathrm{F}$ to $+625^{\circ} \mathrm{F}$. We have plastic encapsulated integral lead wire gages for those of you who have to take them into the field. And we have next day shipping on items in stock and 14-21 days on back orders.

In short, for routine experimental stress analysis work, there are only two things we don't have for sure: our competitors' prices and your next order. We're pleased about the former and trying to remedy the latter ... and that's a good reason to give us a try! Write or call for a catalog and compare our specifications with what you're now using. We think you'll be pleasantly surprised.

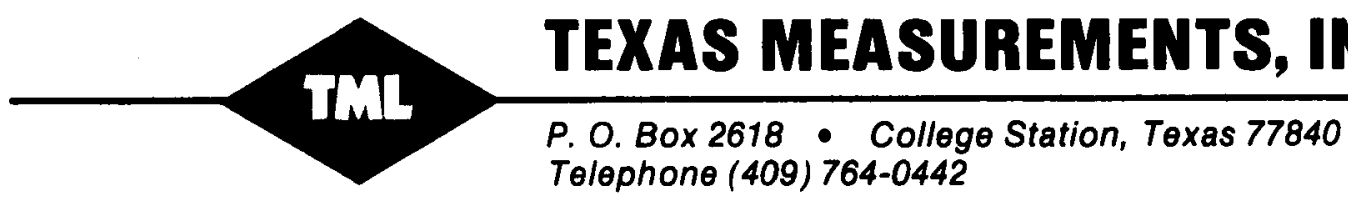

